\title{
Long-Term Follow-up of Intrastromal Corneal Ring Segment Implantation in Pediatric Keratoconus
}

\author{
José F. Alfonso, MD, PhD, * Luis Fernández-Vega-Cueto, MD, PhD, * Carlos Lisa, MD, PhD,* \\ Tiago Monteiro, MD, † and David Madrid-Costa, PhD $\neq$
}

\begin{abstract}
Purpose: To evaluate efficacy, safety, and stability of Ferrara-type intrastromal corneal ring segment (ICRS) implantation for visual rehabilitation in pediatric patients with keratoconus.
\end{abstract}

Methods: This study included patients with keratoconus aged 18 years or younger who had received Ferrara-type ICRS implantation. The uncorrected and corrected distance visual acuities, residual refractive errors, and root mean square for coma-like aberration were recorded preoperatively and at 6 months, 1, 3, and 5 years postoperatively.

Results: One hundred eighteen eyes of 88 patients (mean age 16.1 \pm 1.89 ; range 10-18) were studied. All patients were examined at a 6-month follow-up after ICRS implantation, and at the 12-, 36-, and 60-month follow-ups, 97, 71, and 23 eyes were evaluated, respectively. Mean uncorrected distance visual acuity (logarithm of minimum angle of resolution) changed from $0.67 \pm 0.37$ preoperatively to $0.37 \pm 0.30,6$ months after ICRS implantation $(P<0.0001)$. Mean corrected distance visual acuity increased in turn from $0.19 \pm 0.15$ to $0.10 \pm 0.12(P<0.0001)$. The percentage of eyes with a refractive cylinder $\leq 2.00 \mathrm{D}$ increased from $30.5 \%$ before surgery to $70.3 \% 6$ months later, and the root mean square for corneal coma-like aberration showed a statistically significant decrease $(P<0.001)$. At the follow-up visits, refractive and visual values remained stable compared with those of the 6-month visit.

Conclusions: Our long-term results suggest that Ferrara-type ICRS implantation is a safe, effective, and stable procedure for restoring vision in pediatric patients with keratoconus.

Key Words: keratoconus, intrastromal corneal ring segment

(Cornea 2019;00:1-7)

$\mathrm{K}$ eratoconus is a disorder of the cornea that produces abnormalities, such as high regular and irregular astig-

Received for publication November 10, 2018; revision received January 31, 2019; accepted February 22, 2019.

From the *Fernández-Vega Ophthalmological Institute, Oviedo, Spain; $\dagger$ Hospital de Braga, Braga, Portugal; and \$Optometry and Vision Department, Faculty of Optics and Optometry, Universidad Complutense de Madrid, Madrid, Spain.

The authors have no funding or conflicts of interest to disclose

Correspondence: José F. Alfonso, MD, PhD, Instituto Oftalmológico Fernández-Vega, Avda. Dres. Fernández-Vega 34, 33012 Oviedo, Spain (e-mail: j.alfonso@fernandez-vega.com).

Copyright (C) 2019 Wolters Kluwer Health, Inc. All rights reserved. matism and increased higher-order aberrations, with adverse effects on visual quality in the patients concerned. ${ }^{1,2}$ The impact of this corneal disease depends on its severity; the more advanced the stage of keratoconus, the greater the decline in visual quality. Considering that keratoconus in the pediatric population is usually more severe and progresses faster than in adults, ${ }^{3-5}$ it is clear that, in this group, it is crucial to address 2 challenges, namely to slow down progression and to minimize the impact of the disease on the visual quality of the patient.

Regarding disease stabilization, in light of the results published, it appears that cross-linking (CXL) is effective in slowing down progression in the pediatric population, ${ }^{6-8}$ although some patients (around $20 \%{ }^{8}$ ) might require retreatment. An important question to consider is whether this procedure should be carried out in all cases of pediatric keratoconus. Some authors have suggested initiating this treatment as soon as the diagnosis is confirmed, ${ }^{5}$ whereas a recent study ${ }^{9}$ concluded that there is no urgency in treating these patients where there is no proof of progression.

Beyond keratoconus stabilization, the other important challenge is to improve visual quality. Intrastromal corneal ring segment (ICRS) implantation has proven to be sound and efficacious in mitigating corneal abnormalities and improving visual quality in adult patients with this disease, ${ }^{10-12}$ but few studies have dealt with this procedure for visual rehabilitation in children. ${ }^{13,14} \mathrm{~A}$ recent study ${ }^{13}$ has evaluated the safety and visual results of ICRS implantation, followed by CXL in child keratoconus, and the findings suggest that ICRS implantation is safe and effective for visual rehabilitation in this segment of the population. Given the aforementioned discrepancy regarding the best moment for CXL treatment in the pediatric population, and whether CXL should be used to treat all cases, ${ }^{5,9} 2$ questions arise concerning the management of these patients, namely, whether CXL treatment is needed after ICRS implantation in all cases, and whether the efficacy outcome of ICRS implantation previously reported ${ }^{13}$ would have been less positive in a long-term follow-up if treatment with CXL had not been applied.

In the current study, we present the 5-year, long-term visual and refractive results of ICRS implantation in a large sample of pediatric keratoconus patients.

\section{PATIENTS AND METHODS}

This study was a longitudinal retrospective analysis of the long-term results of Ferrara-type ICRS implantation (AJL 
Ophthalmic, Spain) in keratoconus patients aged 18 years or younger and was carried out at the Fernández-Vega Ophthalmological Institute in Oviedo, Spain. The tenets of the Declaration of Helsinki were followed and full ethical approval from the Institute was obtained. After receiving a full description of the nature of the study and possible consequences of surgery, all patients provided informed consent.

Inclusion criteria were pediatric patients diagnosed with keratoconus, contact lens intolerance, and a clear cornea, along with a minimum corneal thickness of over $400 \mu \mathrm{m}$ at the optical zone involved in the implantation (a general criterion for surgery). Diagnosis of keratoconus was established by the combination of computerized videokeratography of the anterior and posterior corneal surfaces (Sirius, CSO, Italy), K readings, and corneal pachymetry. ${ }^{15-17}$ Grading of keratoconus was based on Amsler-Krumeich classification. The exclusion criteria defined for the study were patients who had keratoconus stage IV (according to Amsler-Krumeich classification), previous corneal or intraocular surgery, a history of herpetic keratitis, and a diagnosed autoimmune disease or a systemic connective tissue disease.

A complete ophthalmologic examination was performed on all patients before surgery, including uncorrected (UDVA) and best-corrected (CDVA) distance visual acuity, manifest and cycloplegic refractions, keratometry, corneal topography (Sirius), anterior segment optical coherence tomography (Visante Zeiss-Meditec, Germany), endothelial cell count, ultrasonic pachymetry, slit-lamp microscopy, Goldmann applanation tonometry, and binocular indirect ophthalmoscopy. Contact lens use was discontinued 1 month before corneal topography.

All eyes in this study received Ferrara-type ICRS (AJL Ophthalmic) implants, which are made of polymethyl methacrylate and with a triangular cross-section that induces a prismatic effect on the cornea. The optical diameter of the ICRS was $5.0 \mathrm{~mm}$ (AFR5) with a base of $0.6 \mathrm{~mm}$, or $6.0 \mathrm{~mm}$ (AFR6) with a base of $0.8 \mathrm{~mm}$, available in variable thicknesses $(0.15 \mathrm{~mm}$ to $0.30 \mathrm{~mm}$, increasing in $0.05 \mathrm{~mm}$ increments) and with arc lengths of 90, 120, 150, and 210 degrees. The ICRSs were implanted following the nomogram used in previous studies. ${ }^{18-21}$ Two experienced surgeons performed all implantation procedures (J.F.A., C.L.) using a femtosecond laser, and using the procedure described in previous studies. ${ }^{18-21}$ Preoperative medication included proparacaine $0.5 \%$, ciprofloxacin $0.3 \%$, and oxybuprocaine $\mathrm{ClH} 0.2 \%$. The postoperative treatment regimen was a combination of antibiotic (tobramycin, $3 \mathrm{mg} / \mathrm{mL}$ ) and steroid eye drops (dexamethasone, $1 \mathrm{mg} / \mathrm{mL}$ ) (Tobradex; Alcon Laboratories, Inc, Fort Worth, TX) 3 times daily for 2 weeks, and the dose was tapered off over the following 2 weeks.

Patients were scheduled for postoperative clinical evaluation at 1 day, 1 week, 1, 3, and 6 months, 1 year, and then every 2 years thereafter. The clinical measurements taken primarily included manifest refraction, slit-lamp biomicroscopy, UDVA and CDVA [measured on the logarithm of minimum angle of resolution (logMAR)], corneal topography, and corneal aberrometry. The root mean square (RMS) for coma-like aberrations [computed for the Zernike terms $\mathrm{Z}$ $(3,1)$ and $Z(3,-1)]$ was evaluated for a pupil size of
$4.5 \mathrm{~mm}$. The manifest refraction was analyzed using the power vector method proposed by Thibos and Horner. ${ }^{22}$

When compared with a previous visit, refractive instability was defined as an increase of at least $1.5 \mathrm{D}$ in maximum keratometry (measured by Sirius) or an increase of at least $1.5 \mathrm{D}$ in the topographic cylinder and visual instability as a decrease greater than 1 line of CDVA.

Data analysis was performed using SPSS for Windows, version 14.0 (SPSS Inc, Chicago, IL). Normality was checked with the Kolmogorov-Smirnov test, and a repeated-measures analysis of variance and a Bonferroni test were performed to compare the results. Differences were considered to be statistically significant when the $P$ value was $<0.05$. At each follow-up stage, only the patients who attended that visit were included in the statistical analysis.

\section{RESULTS}

The study included 118 eyes of 88 patients with a mean age of $16.1 \pm 1.89$ (range 10-18). ICRSs were successfully implanted in all cases, with no intraoperative or postoperative complications. Table 1 shows patient demographics and preoperative characteristics. All patients were examined at the 6-month follow-up, and Figure 1 shows the efficacy of the ICRS implantation at that time. The mean UDVA (logMAR) changed from $0.67 \pm 0.37$ before ICRS implantation to 0.37 $\pm 0.30,6$ months later $(P<0.0001)$. The mean CDVA, in turn, increased from the preoperative $0.19 \pm 0.15$ to a postoperative $0.10 \pm 0.12(P<0.0001)$. The 6-month efficacy index (mean postoperative UDVA/mean preoperative CDVA) was $0.8 \%$, and $74.5 \%$ of the eyes ( 88 eyes) showed a gain of lines of CDVA (Fig. 2). The 6-month safety index (ratio of postoperative to preoperative monocular CDVA) was 1.2. Figure 3 shows the cumulative distribution of CDVA, before surgery and 6 months later. The percentage of eyes with a CDVA of $0.1 \operatorname{logMAR}$ (about $20 / 25$ or better) increased from $39 \%$ to $73.7 \%$, whereas the percentage of eyes with a CDVA of $0.0 \log$ MAR varied from $5.1 \%$ to $32.2 \%$.

The spherical equivalent decreased from a preoperative $-1.77 \pm 2.36 \mathrm{D}$ to a postoperative value of $-1.08 \pm 1.88 \mathrm{D}$ $(P=0.0005)$. The blur strength $(\mathrm{B})$ value, in turn, dropped

\section{TABLE 1. Patient Demographics}

\begin{tabular}{lc}
\hline Characteristic & Value \\
\hline Eyes (n) & 118 \\
Age (yr) & $16.1 \pm 1.89(10$ to 18$)$ \\
Gender (Male/Female) (\%) & $80.5 / 19.5$ \\
Spherical equivalent (D) range & $-1.77 \pm 2.35(+2.25$ to -9.5$)$ \\
Refractive cylinder (D) range & $-3.64 \pm 2.48(0.00$ to -11.50$)$ \\
Minimum K (D) range & $45.32 \pm 2.77(40.75$ to 55.00$)$ \\
Maximum K (D) range & $49.47 \pm 4.03(43.50$ to 58.00$)$ \\
Mean central K (D) range & $47.18 \pm 2.88(42.25$ to 55.00$)$ \\
Comatic aberration $(\mu \mathrm{m})$ range & $1.56 \pm 0.89(0.38$ to 4.50$)$ \\
\hline
\end{tabular}

Age, pre-ICRS implantation spherical equivalent, refractive cylinder, pre-keratometry $(\mathrm{K})$ readings and pre-comatic aberration (means $\pm \mathrm{SD}$ and range). 
FIGURE 1. UDVA and CDVA before and 6 months after ICRS implantation (efficacy).

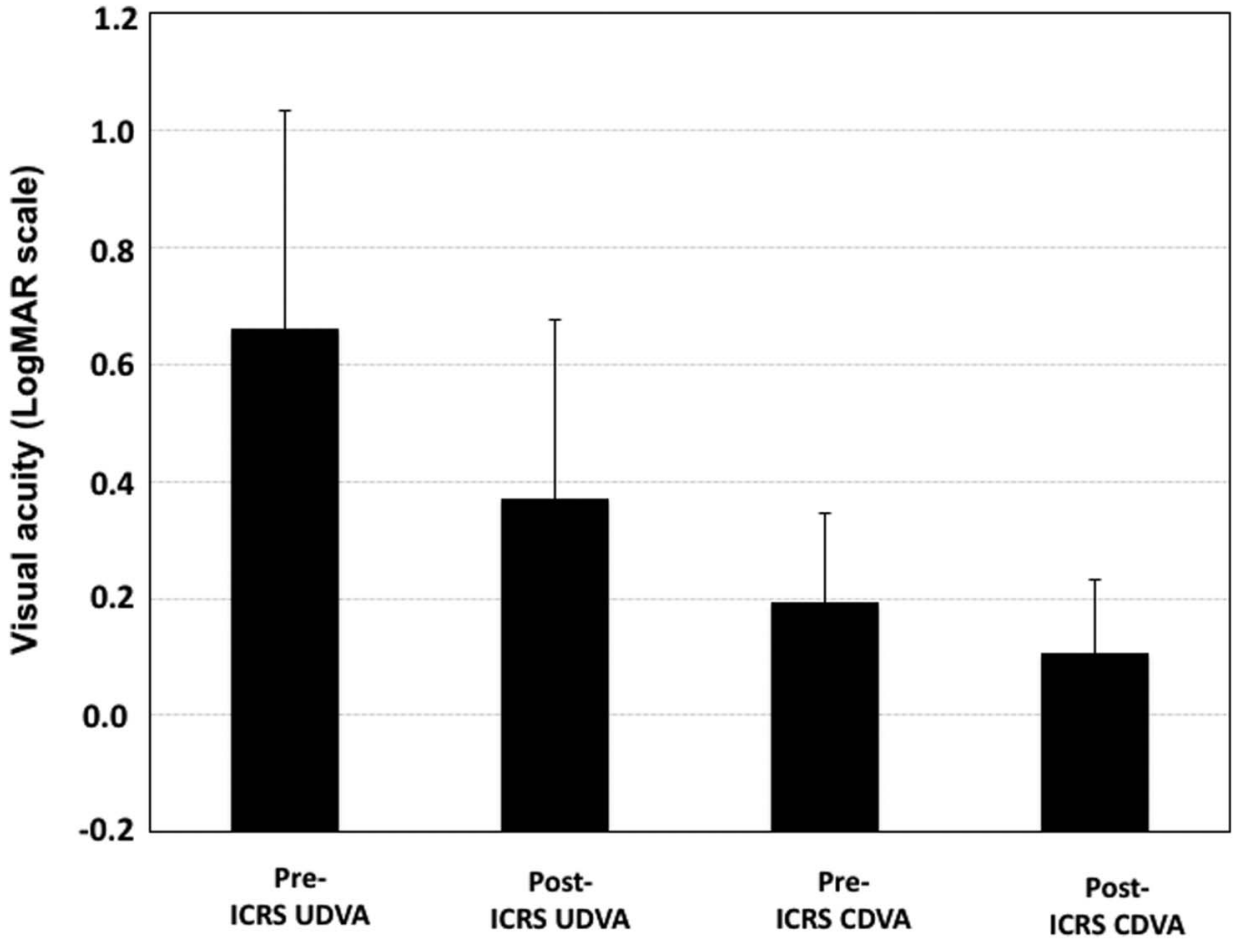

The mean maximum $\mathrm{K}$ reading declined from a pre-implant $49.47 \pm 4.03 \mathrm{D}$ to a post-implant value of $47.64 \pm 3.02 \mathrm{D}$ $(<0.0001)$, whereas the mean minimum reading dipped from $45.32 \pm 2.77 \mathrm{D}$ to $44.99 \pm 2.40 \mathrm{D}(P=0.03)$. The RMS for corneal coma-like aberration for a $4.5-\mathrm{mm}$ pupil changed from $1.56 \pm 0.89 \mu \mathrm{m}$ to $1.14 \pm 0.87 \mu \mathrm{m}(P<0.001)$.
FIGURE 2. Change in CDVA 6 months after ICRS implantation (safety).

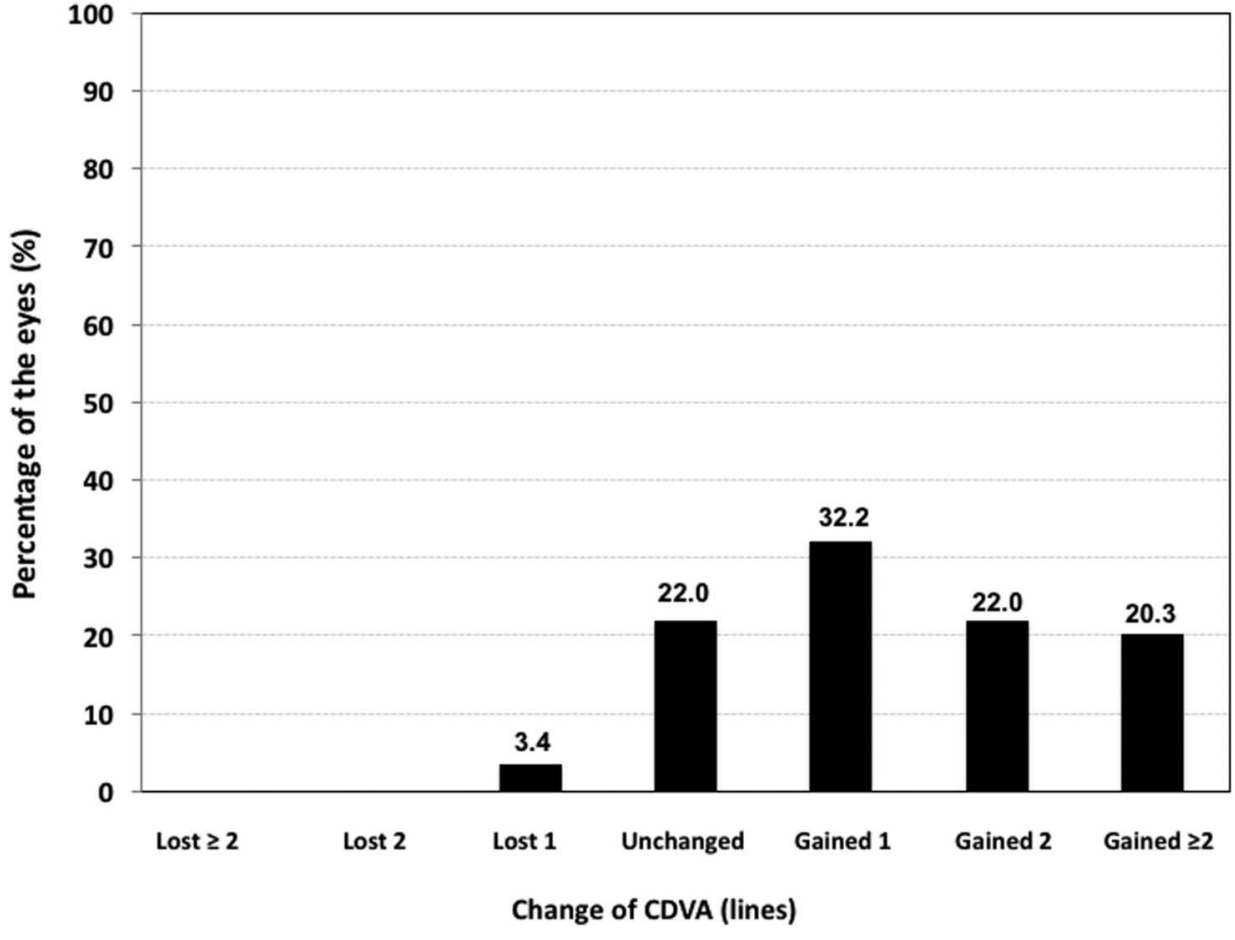

www.corneajrnl.com | 3 


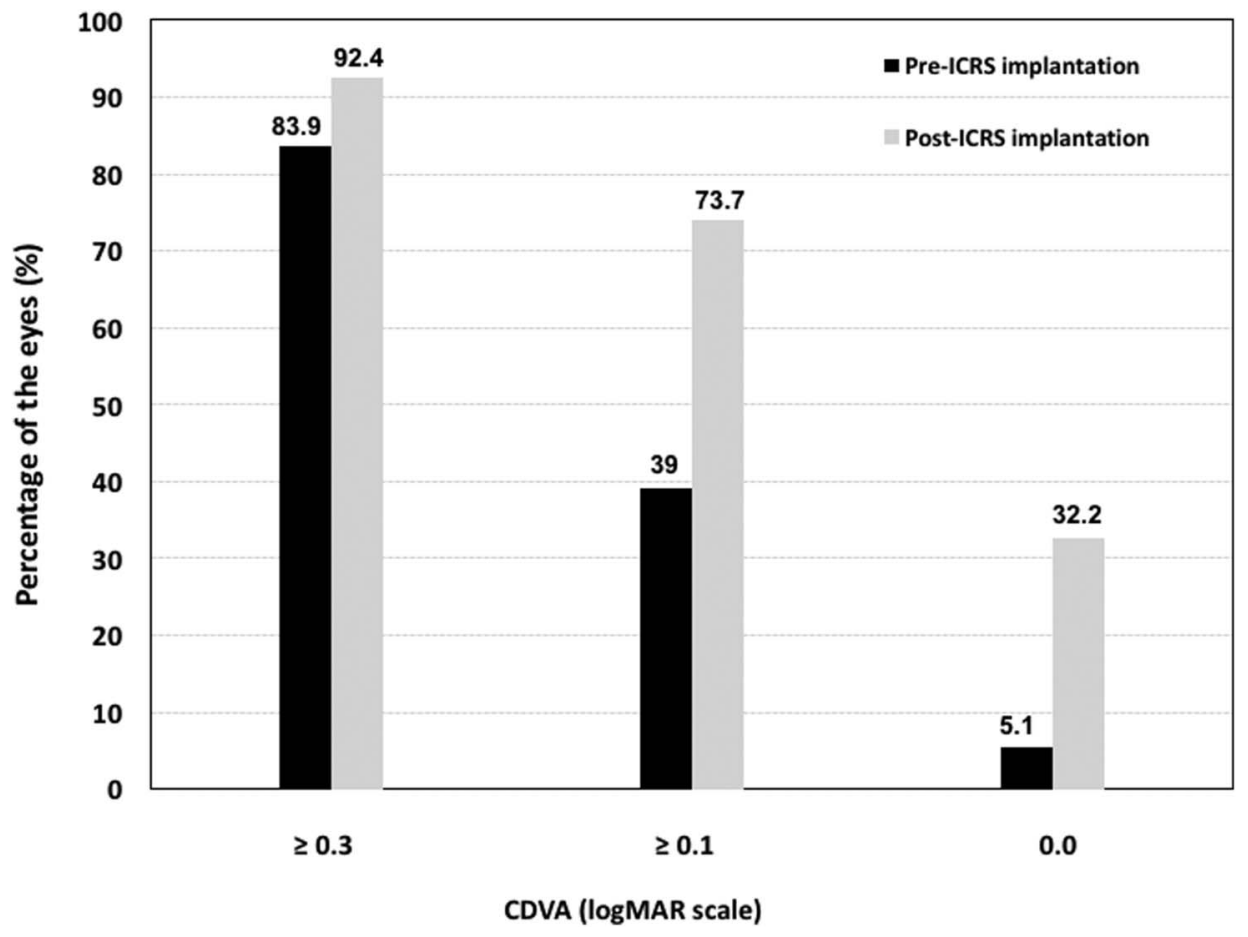

FIGURE 3. Plot comparing the cumulative CDVA before and 6 months after surgery.

higher than $1.5 \mathrm{D}$. In these 5 eyes, the CDVA values were

Visual and Refractive Stability: 12-

Month Follow-up

Seventy-four patients (97 eyes) attended the 6- and 12month follow-up visits. All visual acuity and refractive parameters analyzed were stable over this period (Table 2). During this postoperative period, only 1 eye had lost 2 lines of CDVA. Two eyes had an increase of $1.75 \mathrm{D}$ of topographic cylinder and 3 eyes had an increase in maximum keratometry maintained between the 6- and 12-month visits.

\section{Visual and Refractive Stability: 36-}

\section{Month Follow-up}

Fifty-seven patients (71 eyes) completed the 6-, 12-, and 36-month follow-up visits. All visual and refractive

FIGURE 4. Representation of the astigmatic vector (J0 and J45) before and 6 months after ICRS implantation.

4 | www.corneajrnl.com

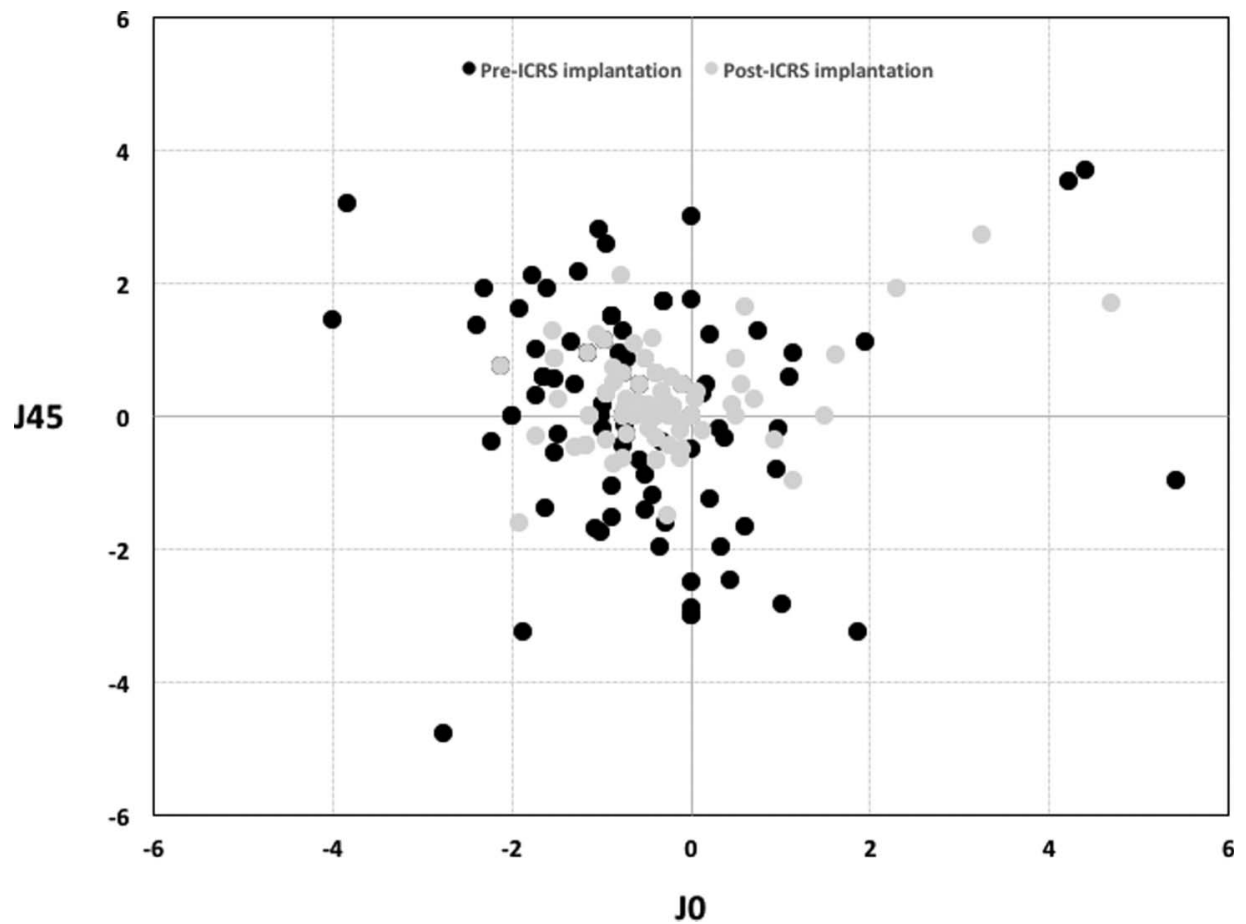

Copyright (C) 2019 Wolters Kluwer Health, Inc. All rights reserved. 
TABLE 2. Visual and Refractive Results at the 6- and 12-Month Follow-up

\begin{tabular}{|c|c|c|c|}
\hline Characteristic & & & Value \\
\hline Eyes (n) & & & 97 \\
\hline Characteristic & $\begin{array}{c}\text { 6-Month } \\
\text { Follow-up }\end{array}$ & $\begin{array}{l}\text { 12-Month } \\
\text { Follow-up }\end{array}$ & $P$ Value \\
\hline UDVA (logMAR) & $0.38 \pm 0.29$ & $0.37 \pm 0.27$ & 0.35 \\
\hline CDVA (logMAR) & $0.11 \pm 0.11$ & $0.11 \pm 0.13$ & 0.39 \\
\hline Mean spherical equivalent (D) & $-1.24 \pm 1.97$ & $-1.32 \pm 1.98$ & 0.15 \\
\hline Mean refractive cylinder (D) & $-1.89 \pm 1.45$ & $-1.93 \pm 1.46$ & 0.31 \\
\hline Mean minimum K (D) & $45.06 \pm 2.30$ & $45.12 \pm 2.24$ & 0.27 \\
\hline Mean maximum K (D) & $47.46 \pm 2.83$ & $47.61 \pm 2.68$ & 0.11 \\
\hline Comatic aberration $(\mu \mathrm{m})$ & $1.23 \pm 0.90$ & $1.21 \pm 0.89$ & 0.37 \\
\hline
\end{tabular}

parameters analyzed remained stable over this period (Table 3 ). Three eyes lost 2 lines of CDVA between the 12- and 36month visits. Five eyes showed an increase in maximum keratometry higher than $1.5 \mathrm{D}$, and in 2 of these 5 , this finding was accompanied by a change in topographic cylinder higher than 1.5 D, but none of them lost lines of CDVA.

\section{Visual and Refractive Stability: 60- Month Follow-up}

Twenty-one patients (23 eyes) attended the 6-, 12-, 36-, and 60-month follow-up visits. All visual and refractive parameters assessed were stable over this period (Table 4). Between the visit at 36 months and the final visit at 5 years, none of these 18 eyes had lost 2 or more lines of CDVA, or experienced an increase in maximum keratometry $\geq 1.5 \mathrm{D}$, or a change in topographic cylinder $\geq 1.5 \mathrm{D}$.

\section{DISCUSSION}

Keratoconus in the pediatric population progresses faster than in adults ${ }^{3-5}$ and is evidenced by visual deteriora-

TABLE 3. Visual and Refractive Results at the 6-, 12-, and 36Month Follow-up

\begin{tabular}{|c|c|c|c|c|}
\hline \multicolumn{4}{|l|}{ Characteristic } & \multirow{2}{*}{$\frac{\text { Value }}{71}$} \\
\hline Eyes (n) & & & & \\
\hline Characteristic & $\begin{array}{l}\text { 6-Month } \\
\text { Follow-up }\end{array}$ & $\begin{array}{l}\text { 12-Month } \\
\text { Follow-up }\end{array}$ & $\begin{array}{l}\text { 36-Month } \\
\text { Follow-up }\end{array}$ & $\begin{array}{c}P \\
\text { Value }\end{array}$ \\
\hline UDVA (logMAR) & $0.41 \pm 0.30$ & $0.39 \pm 0.27$ & $0.39 \pm 0.25$ & 0.21 \\
\hline CDVA (logMAR) & $0.12 \pm 0.12$ & $0.12 \pm 0.12$ & $0.11 \pm 0.11$ & 0.19 \\
\hline $\begin{array}{l}\text { Mean spherical } \\
\text { equivalent (D) }\end{array}$ & $-1.35 \pm 1.92$ & $-1.38 \pm 1.96$ & $-1.42 \pm 1.87$ & 0.29 \\
\hline $\begin{array}{l}\text { Mean refractive } \\
\text { cylinder (D) }\end{array}$ & $-1.90 \pm 1.33$ & $-1.94 \pm 1.35$ & $-2.10 \pm 1.22$ & 0.09 \\
\hline $\begin{array}{l}\text { Mean minimum } \mathrm{K} \\
\text { (D) }\end{array}$ & $45.15 \pm 2.38$ & $45.11 \pm 2.32$ & $45.37 \pm 2.47$ & 0.1 \\
\hline $\begin{array}{l}\text { Mean maximum } \mathrm{K} \\
\text { (D) }\end{array}$ & $47.42 \pm 2.90$ & $47.49 \pm 2.78$ & $47.76 \pm 2.82$ & 0.06 \\
\hline $\begin{array}{l}\text { Comatic aberration } \\
\qquad(\mu \mathrm{m})\end{array}$ & $1.29 \pm 1.01$ & $1.26 \pm 1.00$ & $1.17 \pm 1.04$ & 0.15 \\
\hline
\end{tabular}

tion. Hence, it is evident that, in child patients, it is particularly important to improve visual performance as promptly as possible to avoid significant deterioration, which could have a negative impact on their quality of life. Recently, Abdelmassih et al ${ }^{13}$ studied the safety and efficacy of sequential ICRS implantation and CXL in treating keratoconus in children. The authors concluded that this combined procedure was safe and effective for visual restoration in patients with this condition and poor CDVA. An interesting question is whether CXL should be carried out in all cases to maintain this positive outcome because there is controversy regarding the right moment for CXL treatment in children. We consider this an important matter because although CXL is a safe and effective treatment in this group, ${ }^{6,7}$ it should not be considered free of potential complications. $^{6}$ Some studies have suggested ${ }^{5}$ that CXL should be performed as soon as possible, even before signs of disease progression appear. However, a recent study ${ }^{9}$ that compared the long-term outcomes of CXL treatment in pediatric patients with the long-term findings of the fellow untreated keratoconic eyes found that the untreated eyes did not exhibit progression during a 5-year follow-up. The authors concluded that it is not urgent to perform CXL treatment in child patients without evidence of disease progression. It would appear, as Perez-Straiozota et $\mathrm{al}^{7}$ commented in his review article about corneal CXL treatment in this population, that the number of studies is limited and "there is still no standardization for management in pediatric patients."

This current study evaluates the long-term visual and refractive outcome of ICRS implantation alone for visual rehabilitation in child patients. The results were recorded at 6 months, 1, 3, and 5 years. One hundred eighteen eyes were examined at the 6-month follow-up, and all the visual and refractive parameters analyzed improved significantly after ICRS implantation. The mean UDVA (logMAR) changed from $0.67 \pm 0.37$ (about 20/100) before ICRS implantation to $0.37 \pm 0.30$ (about 20/50) 6 months later. The percentage of eyes with a CDVA of $0.1 \log$ MAR (about 20/25 or better) increased from $39 \%$ preoperatively to $73.7 \%$ postoperatively. In turn, the percentage of eyes with a refractive cylinder $\leq$ $1.50 \mathrm{D}$ varied from $20.3 \%$ to $61 \%$. Furthermore, the mean maximum and minimum $\mathrm{K}$ reading and the RMS for corneal coma-like aberration declined after implantation. Few previous studies have evaluated the results of ICRS implantation alone in pediatric patients. ${ }^{14,23}$ Khan and Muhtaseb ${ }^{23}$ presented the case of an 11-year-old patient who underwent bilateral implantation of Intacs SK ICRS (Addition Technology, Inc, Lombard, IL) and who experienced a significant improvement in UDVA, CDVA, and refractive error after surgery. A recent study ${ }^{14}$ has analyzed the visual and refractive results of Intacs/Intacs SK ICRS implantation in 14 child keratoconus patients. This study showed that ICRS implantation effected a reduction in the keratometry readings and an improvement in UDVA and CDVA. These encouraging data suggest that ICRS implantation, both alone ${ }^{14,23}$ or in combination with $\mathrm{CXL},{ }^{13}$ is an effective and safe procedure for visual rehabilitation in pediatric patients, allowing them to grow and develop and to exhibit better visual performance. 
TABLE 4. Visual and Refractive Results at the 6-, 12-, 36-, and 60-Month Follow-up

\begin{tabular}{|c|c|c|c|c|c|}
\hline Characteristic & & & & & Value \\
\hline Eyes (n) & & & & & 23 \\
\hline Characteristic & 6-Month Follow-up & 12-Month Follow-up & 36-Month Follow-up & 60-Month Follow-up & $P$ Value \\
\hline CDVA (logMAR) & $0.13 \pm 0.12$ & $0.14 \pm 0.16$ & $0.11 \pm 0.10$ & $0.09 \pm 0.08$ & 0.09 \\
\hline Mean spherical equivalent (D) & $-1.36 \pm 2.57$ & $-1.59 \pm 2.75$ & $-1.57 \pm 2.80$ & $-1.95 \pm 3.70$ & 0.09 \\
\hline Mean refractive cylinder (D) & $-2.11 \pm 1.67$ & $-2.10 \pm 1.67$ & $-2.17 \pm 1.48$ & $-2.15 \pm 1.47$ & 0.36 \\
\hline Mean maximum K (D) & $47.44 \pm 2.54$ & $47.33 \pm 2.25$ & $47.58 \pm 2.54$ & $47.69 \pm 2.50$ & 0.06 \\
\hline Comatic aberration $(\mu \mathrm{m})$ & $1.33 \pm 0.88$ & $1.21 \pm 0.77$ & $1.17 \pm 0.77$ & $1.11 \pm 0.72$ & 0.06 \\
\hline
\end{tabular}

Going beyond this positive visual and refractive outcome at 6 months, the next question to consider is whether these improvements were stable over the long term or, on the other hand, whether it would have been appropriate to apply CXL in all cases to maintain positive visual and refractive results. In the present study, 97 eyes completed the 6- and 12-month follow-up visits; 71 eyes, the 6-, 12-, and 36-month visits; and 23 eyes completed the 6-, 12-, 36-, and 60-month follow-ups. Our results (Tables 2-4) showed that, from the 6-month follow-up and thereafter, visual and refractive ameliorations were stable. Despite this stability, it is interesting to analyze how many eyes experienced visual or refractive instability and, therefore, a combined procedure (ICRS implantation + CXL) would have been a better treatment approach. During the 12-month follow-up period, only 1 eye $(1.03 \%)$ lost 2 lines of CDVA, and 3 eyes $(5.1 \%)$ experienced refractive instability, but without changes in CDVA. In turn, between the 12- and 36month visits, 3 eyes (4.2\%) suffered visual instability, and 5 eyes $(7.0 \%)$ showed refractive instability, but also without changes in CDVA. Finally, between the follow-up at 36 months and the final visit at 5 years, no eyes showed visual or refractive instability. These results imply that, for a high percentage of cases, ICRS implantation alone provides effective, safe, and stable visual and refractive improvement. This outcome is in line with the results obtained by Or et $\mathrm{al}^{9}$ who, after a long-term evaluation of eyes treated with CXL and of similar untreated eyes, concluded that, "there is no urgency in treating paediatric patients with keratoconus without progression. These patients should be closely monitored for the earliest signs of progression, upon which CXL should be promptly offered."

In the present study, because the main aim was to ameliorate visual quality, surgery was scheduled immediately after keratoconus was diagnosed, without waiting to register progression of the disease. Consequently, we cannot confirm whether this procedure slowed down keratoconus progression. However, the mean age of the patients included in this analysis was $16.1 \pm 1.89$ (range 10-18) and it is well established that, at this age, the disease tends to progress more rapidly. ${ }^{3-5}$ What we can state, however, is that Ferrara-type ICRS implantation alone, using a femtosecond laser, is an apparently safe, effective, and stable procedure for visual rehabilitation in pediatric keratoconus. Furthermore, most eyes exhibited visual

6 | www.corneajrnl.com and refractive stability over a 5-year follow-up period, suggesting that in a few cases (around 6\% in the 12-month follow-up period and $11 \%$ between the 12- and 36-month visits) a combined procedure (ICRS implantation and then CXL) might have been a better treatment approach. In their study, Or et $\mathrm{al}^{9}$ hypothesized that treating 1 eye with CXL could make patients more reluctant to touch or rub their eyes, eliminating or diminishing one of the main risk factors in progression, namely eye rubbing, ${ }^{24}$ and could in turn help stabilize keratoconus progression even in the untreated eye. Similarly, undergoing surgery (ICRS implantation) could have the same effect on patients with regard to eye rubbing.

Despite the encouraging results, we would like to note some limitations of the study. The ICRS used in the current study (Ferrara-type rings) are not available in some countries, for example, in the United States. This was a retrospective study and it was not possible to collect all the data from all patients over the entire follow-up. Prospective studies including more cases examined over a longer follow-up period are required to validate the present results. Consequently, these ICRS will be available in more countries.

In summary, present long-term results suggest that Ferrara-type ICRS implantation is a safe and effective procedure for visual restoration in pediatric patients with keratoconus. This procedure reduces refractive error while improving postsurgery UDVA and CDVA. In very few cases was visual and/or refractive instability experienced, and treatment with CXL might have been indicated.

\section{REFERENCES}

1. Krachmer JH, Feder RS, Belin MW. Keratoconus and related noninflammatory corneal thinning disorders. Surv Ophthalmol. 1984;28: 293-322.

2. Rabinowitz YS. Keratoconus. Surv Ophthalmol. 1988;42:297-319.

3. Reeves SW, Stinnett S, Adelman RA, et al. Risk factors for progression to penetrating keratoplasty in patients with keratoconus. Am J Ophthalmol. 2005;140:607-611.

4. Afshari A, Muftuoglu O. Keratoconus clinical findings according to different age and gender groups. Cornea. 2008;27:1109-1113.

5. Chatzis N, Hafezi F. Progression of keratoconus and efficacy of pediatric [corrected] corneal collagen cross-linking in children and adolescents. $J$ Refract Surg. 2012;28:753-758. Erratum in: J Refract Surg. 2013;29:72.

6. McAnena L, Doyle F, O'Keefe M. Cross-linking in children with keratoconus: a systematic review and meta-analysis. Acta Ophthalmol. 2017;95:229-239.

7. Perez-Straziota C, Gaster RN, Rabinowitz YS. Corneal cross-linking for pediatric keratcoconus review. Cornea. 2018;37:802-809. 
8. Mazzotta C, Traversi C, Baiocchi S, et al. Corneal collagen cross-linking with riboflavin and ultraviolet a light for pediatric keratoconus: ten-year results. Cornea. 2018;37:560-566.

9. Or L, Rozenberg A, Abulafia A, et al. Corneal cross-linking in pediatric patients: evaluating treated and untreated eyes-5-year follow-up results. Cornea. 2018;37:1013-1017.

10. Ziaei M, Barsam A, Shamie N, et al. Reshaping procedures for the surgical management of corneal ectasia. J Cataract Refract Surg. 2015;41:842-872.

11. Fernández-Vega-Cueto L, Romano V, Zaldivar R, et al. Surgical options for the refractive correction of keratoconus: myth or reality. $J O p h$ thalmol. 2017;2017:7589816.

12. Giacomin NT, Mello GR, Medeiros CS, et al. Intracorneal ring segments implantation for corneal ectasia. J Refract Surg. 2016;32:829-839.

13. Abdelmassih Y, El-Khoury S, Dirani A, et al. Safety and efficacy of sequential intracorneal ring segment implantation and cross-linking in pediatric keratoconus. Am J Ophthalmol. 2017;178:51-57.

14. Abreu AC, Malheiro L, Coelho J, et al. Implantation of intracorneal ring segments in pediatric patients: long-term follow-up. Int Med Case Rep J. 2018;11:23-27.

15. Maeda N, Klyce SD, Smolek MK. Comparison of methods for detecting keratoconus using videokeratography. Arch Ophthalmol. 1995;113:870-874.

16. Rabinowitz YS, Rasheed K, Yang H, et al. Accuracy of ultrasonic pachymetry and videokeratography in detecting keratoconus. J Cataract Refract Surg. 1998;24:196-201.
17. Elashoff HB, Lim KL. Corneal elevation indices in normal and keratoconic eyes. J Cataract Refract Surg. 2006;32:1281-1287.

18. Lisa C, Fernández-Vega Cueto L, Poo-López A, et al. Long-term followup of intrastromal corneal ring segments (210-degree arc length) in central keratoconus with high corneal asphericity. Cornea. 2017;36: $1325-1330$.

19. Fernández-Vega Cueto L, Lisa C, Poo-López A, et al. Intrastromal corneal ring segment implantation in 409 paracentral keratoconic eyes. Cornea. 2016;35:1421-1426.

20. Fernández-Vega Cueto L, Lisa $\mathrm{C}$, Madrid-Costa $\mathrm{D}$, et al. Long-term follow-up of intrastromal corneal ring segments in paracentral keratoconus with coincident corneal keratometric, comatic, and refractive axes: stability of the procedure. J Ophthalmol. 2017;2017:4058026.

21. Alfonso JF, Fernández-Vega Cueto L, Baamonde B, et al. Inferior intrastromal corneal ring segments in paracentral keratoconus with no coincident topographic and coma axis. J Refract Surg. 2013;29: 266-272.

22. Thibos LN, Horner D. Power vector analysis of the optical outcome of refractive surgery. J Cataract Refract Surg. 2001;27:80-85.

23. Khan MI, Muhtaseb M. Intrastromal corneal ring segments for bilateral keratoconus in an 11-year-old boy. J Cataract Refract Surg. 2011;37: 201-205.

24. Bawazeer AM, Hodge WG, Lorimer B. Atopy and keratoconus: a multivariate analysis. Br J Ophthalmol. 2000;84:834-836. 